1 Universidade Federal do Paraná (UFPR), Núcleo de Estudos em Saúde Coletiva - Curitiba (PR), Brasil. maizatostes@hotmail.com

2 Universidade Federal do Paraná (UFPR), Núcleo de Estudos em Saúde Coletiva - Curitiba (PR), Brasil. guilherme.albuquerque. ufpr@gmail.com

3 Universidade Federal do Paraná (UFPR), Núcleo de Estudos em Saúde Coletiva - Curitiba (PR), Brasil. marcelojss@gmail.com

4 Universidade Federal do Paraná (UFPR) - Curitiba (PR), Brasil.

estatisticoufpr@gmail.com

\section{Sofrimento mental de professores do ensino público}

\author{
Mental distress of public school teachers
}

\author{
Maiza Vaz Tostes', Guilherme Souza Cavalcanti de Albuquerque², Marcelo José de Souza e \\ Silva ${ }^{3}$, Ricardo Rasmussen Petterle ${ }^{\mathbf{4}}$
}

RESUMO Realizou-se estudo transversal do sofrimento mental com 1.021 professores do ensino público do Paraná. Utilizou-se o Self-Report Questionnaire para distúrbios psíquicos menores, os inventários de ansiedade e depressão de Beck, e questionário sociodemográfico e de morbidade autorreferida. Os testes Qui-quadrado, Exato de Fisher e Kruskal-Wallis foram utilizados na análise dos dados obtidos. Foram encontrados distúrbios psíquicos menores em 75\%, depressão em 44\% e ansiedade em 70\% das pessoas observadas no presente estudo, havendo associação significativa $(\mathrm{p}<0,05)$ destes sintomas com o sexo feminino, outras doenças, o fato de levarem trabalho para casa e de trabalharem com o ensino fundamental. O sofrimento mental esteve presente em grande parcela da amostra estudada, apresentando relação com as condições de trabalho.

PALAVRAS-CHAVE Saúde do trabalhador. Estresse psicológico. Professores. Condições de trabalho. Educação.

ABSTRACT A cross-sectional study of mental suffering was carried out with 1.021 professors of the public education in Paraná. The Self-Report Questionnaire was utilized for minor psychic disorders, Beck's anxiety and depression inventories, and a sociodemographic and self-reported morbidity questionnaire. The Chi-square, Exact of Fischer and the Kruskal-Wallis tests were used in the analysis of the obtained data. Minor psychic disorders were found in 75\%, depression in $44 \%$ and anxiety in $70 \%$ of the people observed in the present study, with a significant association $(p<0,05)$ of this symptoms with the female sex, other illness, the fact of taking work home and working with elementary school. Mental distress was present in a large portion of the sample studied, presenting relation with the working conditions.

KEYWORDS Occupational health. Stress psychological. Teachers. Working conditions. Education. 


\section{Introdução}

É através do trabalho que a humanidade, transformando a natureza, se produz, se desenvolve e se transforma. Marx ${ }^{\mathbf{1}}$ já demonstrava que o ser humano se constitui na unidade de sua base biológica com o produto social, resultado do trabalho humano. É através do trabalho pensado, planejado, estruturado para determinada finalidade que o ser humano se produz, modificando a natureza, despertando suas próprias potencialidades e desenvolvendo novas possibilidades para o gênero humano. Diferente dos outros animais, portanto, o humano não está pronto ao nascer; precisa apropriar-se dos produtos humanos, produzidos socialmente, para constituir em si o que caracteriza o gênero humano em cada momento histórico.

Não basta, então, que o gênero humano crie novos modos de agir sobre a natureza, produza novos conhecimentos e desenvolva novas possibilidades. É necessário que todo esse saber seja transmitido para as novas gerações, desenvolvendo a humanidade em cada um. A transmissão histórica do conhecimento produzido, de geração a geração, é de fundamental importância para o desenvolvimento do gênero humano, e isso ocorreu de diversas formas ao longo da história, até que se consolidou na escola, como tarefa do professor. Conforme Saviani,

o trabalho educativo é o ato de produzir, direta e intencionalmente em cada indivíduo singular, a humanidade que é produzida histórica e coletivamente pelo conjunto dos homens ${ }^{2(13)}$.

Se a escola surgiu, na Antiguidade, centrada no adestramento militar e, na Idade Média, voltou-se "à vida 'santa' dos monges e à vida 'cavalheiresca' dos barões"3(113), tornou-se ainda mais importante no capitalismo, para a formação técnica e ideológica da força de trabalho que moveria os meios de produção, permitindo o desenvolvimento vertiginoso alcançado neste modo de produção em comparação com os anteriores.

O professor assumiu, então, a enorme importância de transmitir às novas gerações o conhecimento já produzido pelo gênero humano, sendo determinante para o desenvolvimento da sociedade, em geral, e da condição de humanidade, em cada um, até que aquele desenvolvimento tornasse desnecessário o domínio da ciência pela esmagadora maioria da classe trabalhadora. Se, para a humanização do homem, tal domínio continuou sendo necessário, para o desenvolvimento da força de trabalho sob o capitalismo, não.

A crise do capitalismo, que se evidenciou na década de 1970, provocou, como reação, a acentuação do processo de globalização ao lado do domínio do neoliberalismo. A conjuntura econômica insustentável provocou a reestruturação dos processos de produção, com a introdução de inovações tecnológicas, novos métodos gerenciais e nova divisão mundial do trabalho, exigindo um novo perfil do trabalhador, adequado ao ritmo de produção mais acelerado.

Essas mudanças na esfera da economia e as decorrentes transformações no mundo do trabalho exigem a reforma dos sistemas educativos. A educação orgânica à nova ordem econômica e social redireciona a escola para ajustar-se a essa realidade, postulando um processo educativo para a formação de um novo trabalhador - flexível, polivalente e competitivo. A crise e as mudanças no mundo do trabalho, por elas desencadeadas, exigem que a escola forme um profissional flexível, apto a aprender novas técnicas rapidamente. "Já não se pensa sequer em formar para o posto de trabalho, mas formar para a empregabilidade"4(21).

A formação desse novo trabalhador requer menor apreensão do conhecimento científico historicamente produzido pela humanidade, e maior capacidade de aprender agilmente novas técnicas de produção, baseadas, em geral, na microeletrônica. Um trabalhador disciplinado e flexível, útil para o capitalismo neoliberal, exigindo reformas 
educacionais que priorizam o aprendizado da eficiência, produtividade e racionalidade ${ }^{5}$. Em outras palavras, um trabalhador cuja formação prescinde do domínio dos fundamentos científicos historicamente produzidos pela humanidade, requisitando apenas o adestramento e a ágil adaptação às novas tecnologias, aplicação prática da ciência desenvolvida e estudada por uma minoria, conhecimento não mais disponibilizado para todos.

\section{Os professores}

passam a viver constantemente na dualidade de serem responsáveis pela reprodução de uma cultura dominante individualista e também por personificarem as esperanças de mobilidade social de diferentes camadas populares. Teoricamente, a escola tem o papel de formar indivíduos para serem seres humanos autônomos, críticos e capazes de atuar na sociedade para torná-la melhor, para, desta maneira, também melhorar sua qualidade de vida. No entanto, as mudanças no contexto social e econômico alteraram significativamente o papel do professor e as exigências pessoais e do meio em relação à eficácia de sua atividade6(14).

Ocorre, então, um aprofundamento da polarização da educação, reduzindo, cada vez mais, a parcela da população para a qual é necessário dar acesso ao conhecimento científico consistente. A escola contemporânea perde importância na formação técnica da força de trabalho e passa a assumir mais a responsabilidade de conformar ideologicamente os trabalhadores à nova ordem. Assim, também o professor como transmissor do conhecimento acumulado, passa a ser menos necessário.

A formação simplificada do trabalhador simplificado permite, também, a simplificação do professor, cujo custo de reprodução se reduz. Torna-se possível reduzir seu salário, uma vez que não há mais necessidade de uma formação fundada na sólida apreensão das sistematizações do conhecimento realizadas pela ciência, como ocorria no passado.

Enquanto a valorização dos professores diminui, cresce a cobrança para que a escola cumpra funções antes legadas a outras instituições sociais, como a família. O professor vem assumindo uma gama de funções, além daquelas tradicionalmente conferidas à especificidade de seu trabalho, sendo, ao mesmo tempo, desqualificado e sobrecarregado. Estimular o potencial de aprendizagem dos alunos, ensiná-los a conviver em sociedade, cobrir as lacunas da instituição escolar, garantir a articulação entre escola e comunidade, e buscar, por conta própria, sua requalificação profissional, são algumas das tarefas que ilustram sua atual condição7.

A desvalorização do trabalho do professor se traduz pelo desrespeito por parte dos alunos, baixos salários, carga de trabalho exaustiva, alto número de alunos por classe e pressão por metas de produtividade, fatores responsáveis pelo intenso sofrimento docente ${ }^{8}$. A isto se somam o aumento dos contratos temporários e a perda de garantias trabalhistas; falta de preparo durante a formação; dificuldades na relação com alunos e pais, diante das fragilidades da escola; exigência de adoção de uma pedagogia que não corresponde ao modelo de escola instituído; cumprimento de várias jornadas em diferentes escolas, sobrecarga advinda da assunção de tarefas como preenchimento de relatórios, cálculo de notas e anotações de frequência ${ }^{4}$.

Ao lado disso, aprofunda-se a cobrança sobre os professores diante do aparente fracasso da escola, ocultando a contradição por eles sofrida através da exigência de qualidade em um ensino que atendendo a um sistema de massa, com alta competitividade e recursos precários, em uma conjuntura na qual a escolaridade não é garantia de emprego 4 .

A agressividade e a indisciplina dos alunos também constituem questões bastante citadas na gênese do adoecimento dos professores.

O professor, em seu trabalho, enfrenta 
inúmeros desafios e assume grandes responsabilidades, constituindo uma das categorias profissionais mais sujeitas a apresentar sofrimento mental. A Organização Internacional do Trabalho (OIT) aponta a categoria docente como sendo a segunda a apresentar doenças ocupacionais?.

A literatura demonstra fartamente que a acentuação da exploração e precariedade das condições de trabalho tem resultado em grave prejuízo à saúde de professores e demais trabalhadores. Porém, observa-se um crescente adoecimento entre os docentes nas últimas décadas, e um grande número de pesquisas aponta para o sofrimento mental como uma das formas mais prevalentes deste adoecimento, ligado às novas condições de trabalho'10,11.

Selligman Silva ${ }^{8}$ cita o duplo sentido do trabalho, sendo ele, por um lado, fonte de prazer e realização, contribuindo para estruturar o processo de identidade dos indivíduos, mas também podendo comprometer a saúde do trabalhador, fazendo-o adoecer. Esta dualidade do trabalho é descrita por Marx ${ }^{1}$ como trabalho concreto - a dimensão do trabalho na qual há a produção de um bem útil, a base da constituição de humanidade - e trabalho abstrato - a dimensão do trabalho enquanto simples dispêndio de energia, necessário para a geração do lucro, sem significado em si para o trabalhador, fonte, portanto, de adoecimento.

A redução da importância do trabalho do professor na transmissão do conhecimento e a acentuação de seu papel na reprodução de uma força de trabalho flexível - apenas voltada à empregabilidade - esvaziam de significado o trabalho docente, influenciando negativamente sua saúde.

A crescente incidência de sofrimento mental em professores vem chamando a atenção de pesquisadores por todo o mundo. Bauer et al. ${ }^{\mathbf{2}}$ destacam que diversas pesquisas demonstram o adoecimento mental da categoria docente como um problema cada vez maior em vários países. Os autores citam duas pesquisas que apontam os professores como os servidores públicos que mais abandonam a carreira na Alemanha, principalmente devido a desordens psiquiátricas e psicossomáticas.

Para caracterizar o sofrimento dos professores, fartamente evidenciado e manifestado por meio de um conjunto de sinais do corpo e da psique, como estresse, ansiedade, depressão e fadiga, efeitos negativos da atividade docente na atualidade, introduziu-se a expressão 'mal-estar docente'13. Este é um fenômeno mundial, que acontece concomitantemente a mudanças econômicas de ordem global ${ }^{14}$. Os primeiros registros epidemiológicos de sofrimento docente aconteceram em países como França, Inglaterra e Alemanha, na década de 1970.

Embora haja estudos nacionais e internacionais sobre as mudanças educacionais e a repercussão sobre a saúde mental dos professores, no Paraná não há estudo semelhante. Diante disso, realizou-se a presente pesquisa, visando conhecer a prevalência de sofrimento mental nos professores de tal rede pública e sua associação com alguns aspectos do trabalho docente naquele estado brasileiro.

\section{Metodologia}

Realizou-se estudo transversal com aplicação de questionários aos professores da rede estadual de educação do Paraná. Todos os professores, independentemente do modo de contratação ou tempo de trabalho, foram convidados a participar da pesquisa, por meio de redes sociais, e-mail, panfletos, cartazes e divulgação diretamente nas escolas. Foram incluídos na pesquisa todos os professores que preencheram o termo de consentimento e responderam os questionários até o final. Foram excluídos da pesquisa os professores que não responderam os questionários até o final.

A aplicação dos questionários foi feita por meio de plataforma online criada exclusivamente para este fim. O acesso aos questionários foi liberado apenas uma vez, através 
de senha pessoal - Registro Geral (RG) de cada participante - previamente cadastrada em banco de dados. A coleta dos dados ocorreu de 23 de janeiro de 2014 a 25 de março de 2015.

O primeiro questionário continha questões sobre aspectos sociodemográficos e da morbidade autorreferida. Na sequência, os participantes responderam questionários direcionados a avaliar depressão, ansiedade e Distúrbios Psíquicos Menores (DPM), por serem estas as condições de maior relevância, segundo a literatura. Os questionários utilizados com esse fim foram: o Self-Report Questionnaire-20 (SRQ-20), o inventário de ansiedade de Beck e o inventário de depressão de Beck. O SRQ-20 permite a detecção precoce de sinais e sintomas de comprometimento da saúde mental, sendo recomendado pela Organização Mundial da Saúde (OMS) como um método para identificação dos Distúrbios Psíquicos Menores (DPM). Os DPM designam quadros clínicos em indivíduos com sintomas de ansiedade, depressão ou somatização, mas que não satisfazem a todos os critérios de doença mental, de acordo com a Classificação Estatística Internacional de Doenças e Problemas Relacionados com a Saúde-10 (CID-10). Foram considerados com presença de DPM os professores que responderam sete ou mais questões como 'positivo'.

O inventário de depressão de Beck investiga a presença de sintomas depressivos, e a classificação é feita conforme a soma de pontos das alternativas: de 0 a 15 pontos, considera-se ausência de depressão; de 16 a 20 pontos, considera-se como disforia; de 21 a 30 pontos, considera-se como depressão moderada; e acima de 30 pontos, como depressão grave.

O inventário de ansiedade de Beck, por sua vez, investiga a presença de sintomas de ansiedade, e a classificação é realizada a partir da soma dos pontos das alternativas: de 0 a 9 pontos, considera-se como ansiedade normal (ou mínimo de ansiedade); de 10 a 18 pontos, ansiedade leve; de 19 a 29 pontos, ansiedade moderada; e de 30 a 63 pontos, ansiedade severa.

Para a análise estatística dos dados, utilizaram-se os testes Qui-quadrado, Exato de Fisher e Kruskal-Wallis, além do software R, versão 3.2.2. Foram avaliadas diversas características dos professores. Considerou-se o nível de significância em $5 \%$, sendo estabelecido como significativo se $\mathrm{p}<0,05$.

Foram cumpridos os princípios éticos contidos na Declaração de Helsinki (1964, reformulada em 1975, 1983, 1989, 1996, 2000 e 2008), da Associação Médica Mundial. O presente estudo foi aprovado pelo Comitê de Ética do Setor de Ciências da Saúde da Universidade Federal do Paraná (UFPR), parecer $\mathrm{n}^{0} 223.652$.

\section{Resultados}

Participaram da pesquisa 1.201 professores. Deste total, $78,85 \%$ eram mulheres e $21,15 \%$, homens. Com média de idade de 43,2 anos, variando de 19 a 65 , todos possuíam ensino superior completo: 1.054 tinham especialização; 94, mestrado; 4, doutorado; e 1, pós-doutorado. A carga horária semanal média, em sala de aula, foi de 37,4 horas/semana. A maioria (59,11\%) trabalhava em dois turnos; $34,63 \%$ trabalhavam nos três turnos (manhã, tarde e noite); e apenas $6 \%$ dos professores trabalhavam somente em um turno. $\mathrm{O}$ número máximo de turmas, por professor, foi 41 , sendo a média de 8,5. Do total de professores, $45,37 \%$ lecionavam em 6 a 10 turmas, e $27 \%$, em 11 a 15 turmas diferentes.

Em relação aos ciclos e modalidades de ensino, $83,9 \%$ dos professores trabalhavam com os anos finais do ensino fundamental ( $6^{\circ}$ ao $9^{\circ}$ ano) e $73,3 \%$, com o ensino médio. Ressalte-se que a amostra se constituiu de professores da rede estadual de ensino, e que os anos iniciais da educação fundamental eram (e ainda são) principalmente de responsabilidade dos municípios. O estudo mostrou, ainda, que $11,82 \%$ dos professores 
pesquisados trabalhavam com ensino técnico e 6,74\%, com educação especial.

Com relação aos atuais problemas de saúde, o sofrimento mental foi o mais citado: $29,73 \%$ dos professores relataram alguma forma de adoecimento mental, como depressão, ansiedade e estresse, entre outros; em segundo lugar, apareceram as doenças osteomusculares, como tendinites e lombalgias, com 23,98\%. Doenças otorrinolaringológicas estiveram presentes em 10,07\% dos docentes.

Os DPM, aqui identificados com o auxílio do questionário SRQ-20, tiveram uma prevalência de $75,27 \%$.
Com o recurso do inventário de depressão de Beck, encontrou-se a presença de sintomas depressivos em $44,04 \%$ dos professores; destes, $25,06 \%$ apresentavam depressão leve (disforia) e 18,98\%, depressão moderada ou grave.

Para estabelecer os níveis de ansiedade entre os professores da rede estadual de ensino do Paraná, utilizou-se o inventário de ansiedade de Beck. Entre os professores estudados, apenas 29,89\% apresentavam níveis mínimos de ansiedade. Os demais foram classificados em duas categorias: ansiedade leve $(29,48 \%)$ e ansiedade moderada ou grave $(40,63 \%)$.

Tabela 1. Sofrimento mental nos professores da rede estadual de ensino do estado do Paraná

\begin{tabular}{lr}
\hline Tipo de sofrimento & $\%$ \\
\hline Distúrbios psíquicos menores presentes & 75,27 \\
Mínimo de ansiedade & 29,89 \\
Ansiedade leve & 29,48 \\
Ansiedade moderada ou grave & 40,63 \\
Ausência de sintomas depressivos & 55,95 \\
Disforia & 25,06 \\
Depressão moderada ou grave & 18,98 \\
\hline
\end{tabular}

Fonte: Elaboração própria.

Observou-se, no presente estudo, maior prevalência de sofrimento mental nas mulheres, em relação aos homens (gráfico 1), o que se repetiu nos três questionários aplicados (DPM, depressão e ansiedade), porém apenas a ansiedade apresentou relevância estatística $(p<0,0001)$.
Quanto ao afastamento do trabalho por motivo de doença, $26,72 \%$ dos professores relataram-no por sofrimento mental.

No que se refere a medicamentos, $65,53 \%$ dos professores pesquisados relataram uso, sendo $32,31 \%$ deles, drogas psicotrópicas. 
Gráfico 1. Comparação dos níveis de sofrimento mental entre homens e mulheres, docentes da rede estadual de ensino do estado do Paraná

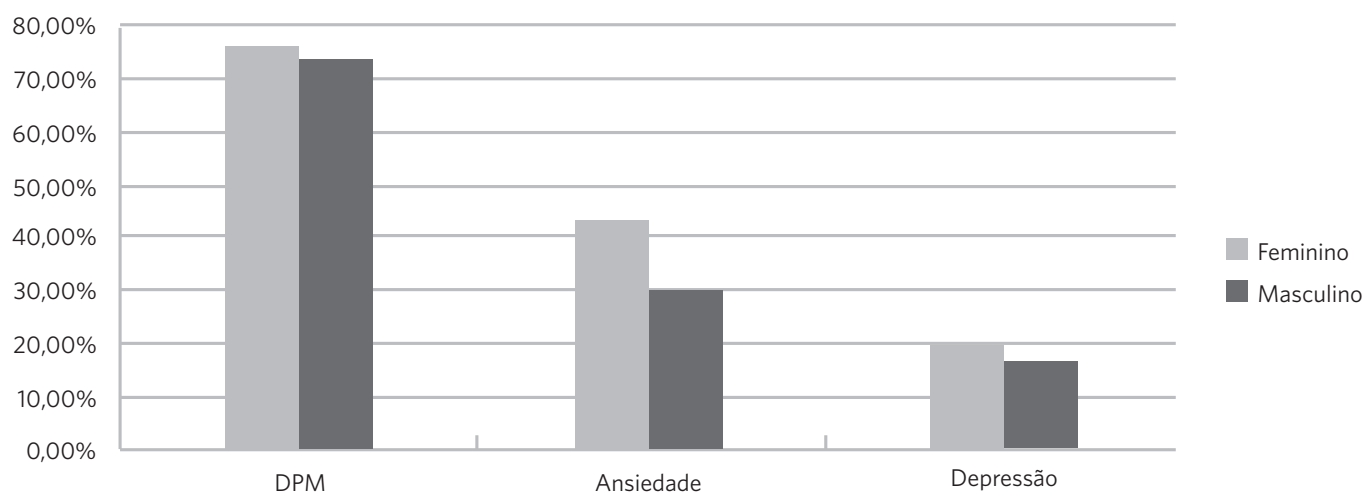

Fonte: Elaboração própria.

Entre os professores entrevistados, $88,09 \%$ referiram que levavam trabalhos para casa; desses, $42,44 \%$ apresentaram ansiedade moderada ou grave, contrastando com os $27,27 \%$ dos que não levavam trabalhos para casa. Essa associação apresentou um $\mathrm{p}<0,0001$, demonstrando ser estatisticamente significativa.

$\mathrm{Na}$ associação de sofrimento mental com o número de turmas, foi possível observar índices de depressão moderada ou grave maiores nos professores com 21 turmas ou mais (33,33\%), enquanto professores com 1 a 5 turmas apresentaram índices de depressão moderada ou grave de $16,34 \%$. Essa associação não foi estatisticamente significativa, porém, foi coerente com a ideia de que, com o aumento do número de turmas, aumenta a sobrecarga de trabalho, o que pode influenciar negativamente a saúde mental do professor.

O número de alunos por turma apresentou relação significativa com a depressão $(\mathrm{p}=0,0467)$. Dos professores que trabalhavam com mais de 40 alunos por turma, 56,57\% apresentaram disforia, enquanto $46,27 \%$ dos que trabalhavam com 30 ou menos alunos na sala apresentaram o mesmo quadro.

Analisando os ciclos em que os professores lecionam, foi possível perceber que aqueles que trabalhavam com o ensino fundamental apresentaram maiores níveis de ansiedade moderada ou grave (42,76\%), em relação aos que não trabalhavam com esse ciclo de ensino (29,53\%). Essa associação obteve um p=0,0018, apresentando relevância estatística. Esse resultado mostrou que trabalhar com o ensino fundamental, ciclo no qual a maioria dos alunos tem de 11 a 15 anos, parece ter influência negativa na saúde mental dos professores.

O tempo de trabalho como professor também apresentou relação com a saúde mental dos docentes: $44,8 \%$ dos que trabalhavam havia mais de 20 anos apresentaram ansiedade moderada ou grave em comparação com os $26 \%$ que trabalhavam de 3 a 5 anos.

Observou-se, também, relação entre a presença de outras doenças e ansiedade $(p<0,0001)$. Professores com doenças otorrinolaringológicas apresentaram maiores níveis de ansiedade. Destes, 78,8\% apresentaram algum nível de ansiedade $(\mathrm{p}=0,0008829)$.

\section{Discussão}

Divergindo da presente pesquisa, na qual o sofrimento mental despontou como mais frequente $(29,73 \%)$, professores de ciências 
do Rio Grande do Sul, pesquisados por Brum et al. ${ }^{14}$, citaram, em sua maioria (27\%), os seguintes diagnósticos: calos nas cordas vocais, lesões por esforços repetitivos, sinusite crônica, hipertensão arterial e lombalgia. A maioria dos estudos, no entanto, demonstrou convergência com os resultados aqui encontrados, mesmo que apresentando índices inferiores de adoecimento.

A prevalência de DPM em trabalhadores, estimada pela OMS, é de cerca de 30\%15. O percentual de professores com DPM encontrado no presente trabalho $(75,27 \%)$ é, portanto, bastante superior ao estimado pela Organização, e também maior do que o encontrado em outras pesquisas realizadas com professores e outras populações.

Lyra et al. $^{16}$ encontraram uma prevalência de $21,8 \%$ de DPM em professores da rede pública de São Gonçalo (RJ). Wernick ${ }^{17}$ encontrou $18,7 \%$ em professores da Universidade Federal da Bahia; Farias ${ }^{18}$, 23,6\% em professores da rede particular de ensino de Salvador (BA); e Souza ${ }^{19}$ encontrou $29,6 \%$ nos docentes da rede pública desse mesmo município.

Entre os estudos que apresentaram índices mais elevados de DPM, destacaram-se alguns realizados com professores da rede municipal, nos quais a prevalência foi de $55,9 \%^{\mathbf{2 0}}$; e nos professores de educação infantil, essa presença foi de $44 \%{ }^{21}$. Em Porto Velho (RO), Jacarandáll identificou a prevalência de $45,5 \%$ de DPM em professores da rede estadual.

Pesquisa realizada em várias cidades do Brasil demonstrou o índice de $25 \%$ de exaustão emocional nos professores estudadosio. Estudo de Bauer et al.12, realizado com professores da Alemanha, demonstrou uma prevalência de $29,8 \%$ de transtornos mentais, porém é preciso considerar que o instrumento utilizado na pesquisa tenha sido o General Health Questionnaire-12 (GHQ-12). Esse mesmo questionário foi utilizado por Jardim et al.22 em um estudo com professoras do ensino fundamental da rede municipal de
Belo Horizonte (MG), na qual foram encontrados $50 \%$ de casos de transtornos mentais.

Todas essas pesquisas mostraram valores bastante inferiores aos $75,27 \%$ encontrados no presente trabalho. Deve-se levar em consideração que, neste estudo, a amostra ocorreu por adesão voluntária dos professores, o que talvez tenha selecionado aqueles que, pelo sofrimento sentido, tiveram maior interesse no tema. Percebe-se, no entanto, que os níveis de sofrimento mental entre os professores das escolas brasileiras, em geral, estão bastante elevados, se comparados com os de outros estratos da população.

Estudo de Botti et al. ${ }^{23}$ com moradores de rua de Belo Horizonte (MG) demonstrou uma prevalência de 49,8\% de DPM. Em cuidadoras familiares de idosos com demência, a prevalência encontrada foi de 46,55\% de DPM ${ }^{24}$. Estudantes de medicina da Universidade de Botucatu, em São Paulo (SP), apresentaram 44,7\% de DPM ${ }^{25}$.

Minayo et al. ${ }^{26}$ observaram, na cidade do Rio de Janeiro (RJ), uma prevalência de DPM de $33,6 \%$ para os policiais militares e $20,3 \%$ para os policiais civis. Pesquisas com outras categorias profissionais demonstraram prevalências ainda menores de DPM, como as realizadas com os metalúrgicos, que apresentaram 19\%; os trabalhadores de processamentos de dados, $20 \%$ a $24 \%$; os trabalhadores de hospitais, $20,8 \%$; os enfermeiros, $33,3 \% \mathbf{2 0}$; além dos bancários, com prevalência de 11,5\% entre os homens e $19,8 \%$ entre as mulheres ${ }^{27}$.

$\mathrm{Na}$ população geral, encontrou-se prevalência de DPM de 39,4\% em mulheres de Feira de Santana (BA) ${ }^{\mathbf{2 8}}$; $35 \%$ em moradores de Olinda (PE) ${ }^{\mathbf{2 9}}$; e $28,5 \%$ na população de Pelotas $(\mathrm{RS})^{30}$.

Com relação aos resultados obtidos na presente pesquisa, a partir da utilização do inventário de depressão de Beck (sintomas depressivos em 44,04\% dos professores, sendo $25,06 \%$ depressão leve disforia - e 18,98\% depressão moderada ou grave), valores próximos foram obtidos em estudo de Freitas et al. ${ }^{\mathbf{3 1}}$, com professores 
universitários do Rio Grande do Norte, quando $50 \%$ apresentaram algum grau de depressão: $42 \%$ com sintomas de depressão leve e $8 \%$ com sintomas de depressão moderada. Esses valores apresentaram-se bastante acima dos encontrados entre professores da região da Associação dos Municípios do Entre Rios (Amerios), de Santa Catarina, e da Associação dos Municípios do Extremo Oeste de Santa Catarina (Ameosc), onde 25\% a $32 \%$ dos professores apresentaram algum grau de depressão $0^{32}$.

A prevalência de depressão na população de países em desenvolvimento, como o Brasil, é de $9 \%$. Sendo um pouco mais alta em países desenvolvidos, como os Estados Unidos e alguns da Europa, girando em torno de $12 \%{ }^{33}$. Percebe-se, de qualquer forma, que a amostra de professores estudada no presente trabalho apresenta um índice de depressão bastante elevado, em relação aos dados disponíveis sobre a população em geral.

Os níveis de ansiedade encontrados neste estudo (29,89\% apresentavam níveis mínimos de ansiedade; 29,48\%, ansiedade leve; e $40,63 \%$, ansiedade moderada ou grave) também são bastante preocupantes. Tais níveis de ansiedade são danosos, e não apenas para o exercício da profissão. Segundo Haslam et al. ${ }^{\mathbf{3 4}}$, os quadros ansiosos geram preocupação, fadiga, dificuldades de concentração e distúrbios do sono, entre outros que podem acarretar prejuízos à funcionalidade global do professor, além de prejudicar o desempenho no trabalho e aumentar os riscos de acidentes.

Pesquisa realizada por Santos et al. ${ }^{35} \mathrm{com}$ professores de escolas públicas da periferia de Paranavaí (PR) mostrou índices de ansiedade parecidos com os encontrados quando se considera algum nível de ansiedade, $70,25 \%$. Strieder ${ }^{32}$ estudou a ansiedade em professores da região de Amerios e Ameosc, em Santa Catarina, encontrando, respectivamente, $64,43 \%$ e $67,73 \%$ de algum grau de ansiedade, sendo, como na citada pesquisa de Santos et $a l .^{35}$, predominantemente níveis leves de ansiedade: $34,56 \%$ e $34,73 \%$, respectivamente.

No que diz respeito à presença de sofrimento mental conforme o gênero, assim como no presente estudo, uma maior prevalência em mulheres, em relação aos homens, foi constatada em inúmeras outras pesquisas, não apenas com professores, como também com a população em geral. Araújo e Carvalho ${ }^{28}$ sugeriram a sobrecarga do trabalho doméstico como um dos possíveis fatores que aumentavam a vulnerabilidade das mulheres para o sofrimento mental. Piccinelli e Wilkinson ${ }^{36}$ apresentaram uma revisão crítica sobre as possíveis relações entre gênero e depressão. As mulheres foram citadas como mais propensas a sofrerem depressão, porém não houve explicação para essa diferença, sugerindo-se, assim, que as experiências durante a infância, as regras e os costumes da sociedade na qual as mulheres estavam inseridas, bem como as diferenças e variações hormonais às quais estavam sujeitas, entre outros itens, estivessem envolvidas em tal causalidade.

Na pesquisa de Delcor ${ }^{21}, 45,8 \%$ das professoras apresentaram DPM, enquanto nos homens, o valor encontrado foi de $22 \%$. Capitão e Mesquista ${ }^{37}$, em pesquisa sobre a prevalência de depressão em trabalhadores de uma frente de trabalho no estado de São Paulo, encontraram 24\% de algum grau de depressão entre os homens e $40 \%$ entre as mulheres. Pesquisa com professores na Alemanha mostrou, também, uma diferença entre homens e mulheres, em relação ao adoecimento mental, com prevalência de $31,5 \%$ entre elas e $28,8 \%$ entre eles ${ }^{12}$. No presente trabalho, a prevalência de DPM entre as mulheres foi de $60,71 \%$, sendo de $51,85 \%$ entre os homens. Em relação à ansiedade moderada ou grave, as mulheres apresentaram 52,97\%, e os homens, $39,51 \%$. A prevalência de algum grau de depressão entre as professoras foi de $67,86 \%$ e de $54,32 \%$ entre os professores.

Entre os participantes da presente 
pesquisa, $26,72 \%$ dos afastamentos do trabalho foram motivados por sofrimento mental, reafirmando a importância desse tipo de situação na vida dos professores. Gasparini, Barreto e Assunção ${ }^{7}$, analisando os perfis de afastamento do trabalho por doença dos servidores da educação de Belo Horizonte (MG), cujos $84,2 \%$ da amostra eram constituídos por professores, encontraram, também, em primeiro lugar, os transtornos mentais e de comportamento, com 15,3\% de prevalência; em segundo, as doenças do trato respiratório; e em terceiro, as doenças osteomusculares.

Na pesquisa de Assunção ${ }^{38}$, com professores de Belo Horizonte (MG), 23\% da amostra utilizavam medicamentos para ansiedade e depressão e $11 \%$, para distúrbios do sono, resultados similares aos encontrados no presente estudo $(65,53 \%$ dos professores pesquisados relataram uso de medicamento, sendo $32,31 \%$ psicotrópicos).

Coincidindo com os achados deste estudo, no qual se observou que professores com doenças otorrinolaringológicas apresentaram maiores níveis de ansiedade, Jardim et al. ${ }^{22}$ também encontraram associação entre transtorno mental e pior qualidade de vida relacionada à voz, em professoras da rede municipal de Belo Horizonte (MG). Os docentes que sofriam de doenças osteomusculares também apresentaram altos níveis de ansiedade: $54,16 \%$ deles se enquadraram nos casos de ansiedade moderada ou grave $(p<0,0001)$. Pinheiro et al. ${ }^{39}$ encontraram associação significativa entre dor crônica e altos escores de depressão e ansiedade.

Fica evidente que os professores participantes do presente estudo apresentaram níveis bastante superiores de sofrimento mental, em relação aos da população em geral, o que é preocupante, tanto para a saúde do professor quanto pelas repercussões na qualidade de ensino. Os altos índices desse tipo de adoecimento mental encontrados corroboraram o fato de $84,26 \%$ considerarem seu trabalho insalubre.

\section{Conclusões}

A presente pesquisa apontou que os professores da rede estadual de educação do Paraná apresentaram níveis muito elevados de sofrimento mental (depressão, ansiedade e distúrbios psiquiátricos menores), muito superiores aos encontrados em outros grupos de professores, outras categorias profissionais e/ou outros grupos populacionais. $\mathrm{O}$ gênero feminino e o elevado número de alunos por turma, bem como os fatos de levarem trabalho para casa, lecionarem no ensino fundamental e serem portadores de outras doenças constituíram situações que demonstraram relação estatisticamente significativa com a presença de sofrimento mental. Também o tempo de trabalho como professores demonstrou relação positiva com o sofrimento mental, embora não estatisticamente significativa.

Verifica-se a necessidade de ampliar a investigação, no sentido de melhor compreender a gênese do sofrimento mental dos professores, oferecendo subsídios para a produção de mudanças significativas, visando à melhoria de saúde destes, agindo nos processos determinantes do adoecimento e não através da simples medicalização. A associação entre fatores deve constituir passo inicial e não conclusivo da investigação da determinação da situação. A compreensão profunda da gênese do sofrimento mental dos professores exige o conhecimento dos processos de determinação que ocorrem nos níveis singular, particular e geral, assim como das correlações que se estabelecem entre esses níveis, o que foge do alcance deste trabalho. 


\section{Referências}

1. Marx K. O capital. São Paulo: Nova Cultural; 1988.

2. Saviani, D. Pedagogia histórico-crítica: primeiras aproximações. 8. ed. Campinas: Autores Associados; 2003.

3. Ponce A. Educação e Luta de Classes. 17. ed. São Paulo: Cortez; 2000.

4. Gomes L. Trabalho multifacetado de professores/ as: a saúde entre limites [dissertação] [internet]. Rio de Janeiro: Escola Nacional de Saúde Pública, Fundação Oswaldo Cruz; 2002. 127 p. [acesso em 2018 fev 10]. Disponível em: https://portalteses. icict.fiocruz.br/pdf/FIOCRUZ/2002/gomeslm/ capa.pdf.

5. Kuenzer AZ. Exclusão includente e inclusão excludente: a nova forma de dualidade estrutural que objetiva as novas relações entre educação e trabalho. In: Saviani D, Sanfelice JL, Lombardi JC, organizadores. Capitalismo, trabalho e educação. 3. ed. Campinas: Autores Associados; 2005. p. 77-96.

6. Souza DL. Professor, trabalho e adoecimento: políticas educacionais, gestão do trabalho e saúde [monografia]. São Carlos: Universidade Federal de São Carlos; 2007. 38 p.

7. Gasparini SM, Barreto SM, Assunção AA. O professor, as condições de trabalho e os efeitos sobre sua saúde. Educ. Pesqui. 2005 Maio-Ago; 31(2):189-199.

8. Silva ES. Saúde Mental e Trabalho. In: Costa NR, Tundis SA. Cidadania e loucura: Políticas de Saúde Mental no Brasil. Petrópolis: Vozes; 1987.

9. Vasconcellos CS. Construção do conhecimento em sala de aula. 6. ed. São Paulo: Libertad; 1997.

10. Codo W. Educação: carinho e trabalho. Petrópolis: Vozes; 1999.

11. Jacarandá EMF. Sofrimento Mental e Satisfação no Trabalho: um estudo com professores das escolas inclusivas estaduais de ensino fundamental em Porto Velho, Rondônia [dissertação] [internet]. Brasília, DF: Universidade de Brasília; 2008. 102 p. [acesso em 2018 fev 10]. Disponível em: http://www. repositorio.unb.br/bitstream/10482/1819/1/2008_ ElzaMariaFreitasJacaranda.pdf.

12. Bauer J, Unterbrink T, Hack A, et al. Working conditions, adverse events and mental health problems in a sample of 949 German teachers. Int. Arch. Occup. Environ. Health. 2007 Apr; 80(5):442-449.

13. Esteves JM. O mal-estar docente: a sala de aula e a saúde dos professores. Bauru: EDUSC; 1999.

14. Brum LM, Azambuja CR, Rezer JFP, et al. Qualidade de vida dos professores da área de ciências em escola pública no Rio Grande do Sul. Trab. Educ. Saúde [internet]. 2012 Mar-Jun [acesso em 2018 fev 1]; 10(1):125-145. Disponível em: http://www.scielo.br/ pdf/tes/v10nl/v10nla08.pdf.

15. Vasconcelos AG. Jurisdição e sofrimento mental: O trabalho é simplesmente lócus de manifestação ou um fator concorrente ou constitutivo dos transtornos mentais. Rev. Trib. Reg. Trab. $3^{\text {a }}$ Reg. [internet]. 2010 Jan-Jun [acesso em 2017 mar 12]; 51(81):411436. Disponível em: https://www.juslaboris. tst.jus.br/bitstream/handle/1939/74491/2010_ vasconcelos_antonio_jurisdicao_sofrimento. pdf? sequence $=1 \&$ isAllowed $=y$.

16. Lyra GFD, Assis SG, Njaine K, et al. A relação entre professores com sofrimento psíquico e crianças com problemas de comportamento. Ciênc. Saúde Colet. [internet]. 2009 Jan [acesso em 2016 abr 15]; 14(2):435-444. Disponível em: http://www.scielo. br/pdf/csc/v14n2/a12v14n2.pdf.

17. Wernick R. Condições de saúde e trabalho dos docentes da Universidade Federal da Bahia [dissertação]. Salvador: Universidade Federal da Bahia; 2000. $56 \mathrm{f}$.

18. Farias TF. Voz do professor: relação saúde e trabalho 
[dissertação]. Salvador: Universidade Federal da Bahia; 2004. $158 \mathrm{f}$.

19. Souza CL. Distúrbio vocal em professores da educação básica da cidade de Salvador, Bahia [dissertação]. Salvador: Universidade Federal da Bahia; 2008. 91 p.

20. Reis EJFB, Araújo TM, Carvalho FM, et al. Docência e Exaustão emocional. Educ. Soc. [internet]. 2006 Jan-Abr. [acesso em 2016 abr 15]; 27(94):229-253. Disponível em: http://www.scielo.br/pdf/es/ v27n94/a12v27n94.pdf.

21. Delcor NS. Condições de trabalho e saúde dos professores da rede particular de ensino em Vitória da Conquista [dissertação]. Salvador: Universidade Federal da Bahia; 2003. 121 p.

22. Jardim R, Barreto SM, Assunção AA. Condições de trabalho, qualidade de vida e disfonia entre docentes. Cad. Saúde Pública [internet]. 2007 Out [acesso em 2016 abr 14]; 23(10):2439-2461. Disponível em: https://www.scielosp.org/pdf/csp/v23n10/19.pdf.

23. Botti NCL, Castro CG, Silva AK, et al. Avaliação da ocorrência de transtornos mentais comuns entre a população de rua de Belo Horizonte. Rev. Barbarói [internet]. 2010 Ago-Dez [acesso em 2016 abr 15] 33:178-193. Disponível em: http://www. online.unisc.br/seer/index.php/barbaroi/article/ viewFile/1583/1318.

24. Silva CL, Passos VMA, Barreto SM. Frequência e repercussão da sobrecarga de cuidadoras familiares de idosos com demência. Rev. Bras. Geriatr. Gerontol. [internet]. 2012 [acesso em 2016 jan 22] 15(4):707-731. Disponível em: <http://www.scielo. br/pdf/rbgg/v15n4/11.pdf.

25. Lima MCP, Domingues MS, Cerqueira ATAR. Prevalência e fatores de risco para transtornos mentais comuns entre estudantes de medicina. Rev. Saúde Pública [internet]. 2006 [acesso em 2016 jan 22] 40(6):1035-1041. Disponível em: http://www. scielo.br/pdf/rsp/v40n6/11.pdf>.
26. Minayo MCS, Assis SG, Oliveira RVC. Impacto das atividades profissionais na saúde física e mental dos policiais civis e militares do Rio de Janeiro (RJ, Brasil). Ciênc. Saúde Colet. [internet]. 2011 [acesso em 2016 mar 12] 16(4):2199-2209. Disponível em: http://www.scielo.br/pdf/csc/v16n4/v16n4al9.

27. Beltrão IK, Duchiade MP, Chor D, et al. Pesquisa de Saúde dos Associados da CASSI [relatório final]. Rio de Janeiro: Fiocruz; 1996.

28. Araújo TM, Carvalho FM. Condições de trabalho docente e saúde na Bahia: estudos epidemiológicos. Educ. Soc. [internet]. 2009 Maio-Ago [acesso em 2016 jan 23] 30(107):427-449.

29. Ludermir AB, Melo Filho DA. Condições de vida e estrutura ocupacional associadas a transtornos mentais comuns. Rev. Saúde Pública [internet]. 2002 [acesso em 2016 mar 22] 36(2):213-21. Disponível em: http://www.scielo.br/pdf/rsp/ v36n2/9214.pdf.

30. Costa JSD, Menezes AMB, Olinto MTA, et al. Prevalência de distúrbios psiquiátricos menores na cidade de Pelotas, RS. Rev. Bras. Epidemiol. [internet]. 2002 [acesso em 2016 mar 23] 5(2):164173. Disponível em: <http://www.lume.ufrgs.br/ bitstream/handle/10183/106485/000937888. pdf;sequence $=1=>$.

31. Silva TR, Carvalho EA. Depressão em professores universitários: uma revisão da literatura brasileira. Rev. Uningá Review [internet]. 2016 out-dez [acesso em 2017 mar 12]; 28(1):113-117. Disponível em: https://www.mastereditora.com.br/periodico/20161005_005442.pdf.

32. Strieder R. Depressão e ansiedade em profissionais da educação das regiões da Amerios e da Ameosc. Rev. Roteiro [internet]. 2009 [acesso em 2017 fev 2]; 34(2):243-268. Disponível em: https://www.dialnet. unirioja.es/servlet/articulo? codigo=3063349.

33. Kessler RC, Ormel J, Petukhova M, et al. Development of lifetime comorbidity in the World 
Health Organization world mental health surveys. Arch. Gen. Psyquiatry [internet]. 2011 Jan [acesso em 2017 fev 2]; 68(1):90-100. Disponível em: http:// www.public-files.prbb.org/publicacions/2a4led309ce7-012f-264a-263316c03650.pdf.

34. Haslam C, Atkinson S, Brown SS, et al. Anxiety and depression in the workplace: effects on the individual and organization. J. Affect. Disord. [internet]. 2005 [acesso em 2017 jan 18]; 88(2):209-215. Disponível em: https://www.ncbi.nlm.nih.gov/ pubmed/16122810.

35. Santos AS, Oliveira AS, Souza VD, et al. A incidência do nível de ansiedade dos docentes dos estabelecimentos de periferia participantes do projeto cultura docente do município de Paranavaí-PR. Col. Pesq. Educ. Física [internet]. 2010 [acesso em 2016 nov 3]; 9(1):43-48. Disponível em: http://www.fontouraeditora.com.br/periodico/upload/550_1502736833. pdf.

36. Piccinelli M, Wilkinson G. Gender differences in depression: critical review. Br. J. Psychiatr. [internet]. 2000 [acesso em 2016 set 1]; 177:486-492. Disponível em: http://www.bjp.rcpsych.org/content/177/6/486/full-text.pdf+html.
37. Capitão CG, Mesquita KL. A depressão em trabalhadores de uma frente de trabalho. Rev. Psicol. UnC [internet]. 2005 [acesso em 2016 set 22]; 2(2):93-102. Disponível em: https://www.researchgate.net/publication/237392072_A_Depressao_ em_Trabalhadores_de_uma_Frente_de_Trabalho.

38. Assunção AA. Saúde e mal-estar do(a) trabalhador(a) docente. In: VII Seminário de la Red de estudios sobre Trabalho Docente; 2008 jul 3, 4 y 5; Buenos Aires. Buenos Aires: Agencia Nacional de Promocion Cientifica y Tecnologia; 2008.

39. Pinheiro RC, Uchida RR, Mathias LAST, et al. Prevalência de sintomas depressivos e ansiosos em pacientes com dor crônica. J. Bras. Psiquiatr. [internet]. 2014; [acesso em 2017 jan 2]. 63(3):213-219. Disponível em: http://www.scielo.br/pdf/jbpsiq/ v63n3/0047-2085-jbpsiq-63-3-0213.pdf.

Recebido em 21/10/2017

Aprovado em 02/03/2018

Conflito de interesses: inexistente

Suporte financeiro: não houve 